\title{
Alfalfa snakin-1 prevents fungal colonization and probably coevolved with rhizobia
}

\author{
Araceli Nora García ${ }^{1 \dagger}$, Nicolás Daniel Ayub ${ }^{1 \dagger}$, Ana Romina Fox¹, María Cristina Gómez ${ }^{1}$, María José Diéguez \\ Elba María Pagano ${ }^{1}$, Carolina Andrea Berini ${ }^{2}$, Jorge Prometeo Muschietti ${ }^{3,4}$ and Gabriela Soto ${ }^{1 *}$
}

\begin{abstract}
Background: The production of antimicrobial peptides is a common defense strategy of living cells against a wide range of pathogens. Plant snakin peptides inhibit bacterial and fungal growth at extremely low concentrations. However, little is known of their molecular and ecological characteristics, including origin, evolutionary equivalence, specific functions and activity against beneficial microbes. The aim of this study was to identify and characterize snakin-1 from alfalfa (MSSN1).

Results: Phylogenetic analysis showed complete congruence between snakin-1 and plant trees. The antimicrobial activity of MsSN1 against bacterial and fungal pathogens of alfalfa was demonstrated in vitro and in vivo. Transgenic alfalfa overexpressing MSSN1 showed increased antimicrobial activity against virulent fungal strains. However, MsSN1 did not affect nitrogen-fixing bacterial strains only when these had an alfalfa origin.

Conclusions: The results reported here suggest that snakin peptides have important and ancestral roles in land plant innate immunity. Our data indicate a coevolutionary process, in which alfalfa exerts a selection pressure for resistance to MSSN1 on rhizobial bacteria. The increased antimicrobial activity against virulent fungal strains without altering the nitrogen-fixing symbiosis observed in MSSN1-overexpressing alfalfa transgenic plants opens the way to the production of effective legume transgenic cultivars for biotic stress resistance.
\end{abstract}

Keywords: Antimicrobial peptides, Alfalfa, Evolution, Land plants, Innate immunity, Snakin

\section{Background}

Alfalfa (Medicago sativa L.), known as the "Queen of Forages", is a perennial legume. This species is native to Asia, and is considered one of the first known crops with a cultivation history of at least 3500 years. Due to its strong vitality, high nutritional quality, high yields, high adaptability and multiple uses, alfalfa is the main forage crop produced in temperate regions of the planet. Elite alfalfa cultivars must not only have high forage yields but also maintain their productivity and stands over several years to provide substantial economic benefits. Regarding this complex topic, improved fungal disease resistance has been specifically identified as the critical trait in alfalfa persistence [1]. In this context, it is proposed that the use of snakin-1 peptide (SN1), a powerful

\footnotetext{
*Correspondence: soto.gabrielacinthia@inta.gob.ar

'Equal contributors

'Instituto de Genética Ewald A. Favret (CICVyA-INTA), De los Reseros S/N, Castelar C25 (1712), Buenos Aires, Argentina

Full list of author information is available at the end of the article
}

but poorly studied antimicrobial compound, to improve alfalfa tolerance to virulent fungal pathogens should be explored.

Antimicrobial peptides are present in virtually all organisms and are an ancient and critical component of innate immunity. SN1, the first member of the snakin family to be characterized, was isolated from a crude cell wall preparation of potato (Solanum tuberosum) tubers (StSN1) [2]. This cysteine-rich peptide from potato was found to be active against bacterial and fungal pathogens at extremely low concentrations $\left(\mathrm{EC}_{50}<10 \mu \mathrm{M}\right)$ [3]. The expression pattern of the StSN1 gene suggests that plant SN1 could be a component of constitutive defense barriers, especially those of storage and reproductive plant organs [3]. A second snakin peptide (StSN2), which has a high amino acid identity (30\%) to $S t \mathrm{SN} 1$, was also isolated from a crude cell wall preparation of potato tubers. Consistent with this high amino acid identity, StSN2 is also active at very low concentrations against a wide range of pathogens [4]. In contrast to StSN1, the expression 
of StSN2 is locally induced by wounding and pathogen infection, suggesting a critical role of snakin-2 in both constitutive and inducible defense barriers of plants. These strong antimicrobial activities of snakin peptides have been verified using bacterial and eukaryotic heterologous expression systems [5-7]. Based on the presence of the Gibberellic Acid Stimulated Arabidopsis (GASA) domain and the absence of bioinformatic (e.g. RGD residues) and functional (e.g. toxic activity) data supporting its relationship with cysteine-rich peptides from snakes venoms, StSN1 and StSN2 have been recently renamed as GSL1 and GSL2, respectively $[8,9]$.

Overexpression of SN1 in potato and wheat (Triticum aestivum), SN2 in potato and tomato (Solanum lycopersicum), and snakin-defensin hybrid protein in tobacco (Nicotiana tabacum) and potato restricts pathogen invasiveness and enhances tolerance to bacterial and fungal diseases, without altering the agronomic phenotype of these crops [6,9-12]. Furthermore, disease sensitivity is enhanced by silencing SN2 in wild tobacco (Nicotiana benthamiana), supporting the central role of snakin peptides in plant defense [13]. In addition, it has been recently shown that StSN1 is located in the plant cell wall [14], confirming that snakin peptides are components of the physical barrier and the first line of defense used by plant cells to prevent bacterial and fungal entry [3]. Furthermore, in concordance with the functional classification of snakin peptides as members of the GASA protein family $[4,15,16]$, StSN1 silencing affects cell division, primary metabolism, and cell wall composition [14]. Snakin peptides could have additional functions in plant growth and development beyond their demonstrated function in biotic stress response. In spite of their hypothetical functional similarity, there is little to no phylogenetic reports on the relationship between StSN1 and GASA-related proteins.

The aim of this study was to identify and characterize snakin-1 (MsSN1) gene of alfalfa. The phylogenetic and functional analyses showed here, propose that MsSN1 is an ancestral plant gene involved in biotic stress resistance, suggesting a coevolutionary process, in which alfalfa exerts a selection pressure for resistance to $M s \mathrm{SN} 1$ on rhizobial bacteria.

\section{Methods}

\section{Bacterial and fungal strains}

The bacterial strains (all Gram-negative bacteria) used in this study were: Pseudomonas fluorescens Pf-5 [17], Sinorhizobium meliloti BL225C [18], Sinorhizobium meliloti SM11 [19], Sinorhizobium medicae WSM419 [20], Sinorhizobium fredii USDA 257 [21], Rhizobium sp. Or 191 [22], Rhizobium etli CFN 42 [23], Mesorhizobium loti MAFF303099 [24], Bradyrhizobium japonicum USDA110 [25] and Agrobacterium tumefaciens LBA4404 [26]. The fungal strains used in this work were: Phoma medicaginis strain CT1 and Colletotrichum trifolii strain CT2, isolated from INTA alfalfa cultivars and kindly provided by Dr. Ricardo Comerio (Instituto de Microbiología y Zoología Agrícola, Instituto Nacional de Tecnologia Agropecuaria, Argentina).

\section{Fungus material}

Two fungal pathogens, Phoma medicaginis strain CT1 and Colletotrichum trifolii strain CT2, were grown on PDA (Cat. \# B0216605, Britania) plates at room temperature for approximately 7 days before the start of the bioassay. For spore collection, the plates were flooded with sterile distilled water and scraped with a wire loop. Spore concentration was adjusted to $1 \times 10^{6}$ spores $/ \mathrm{ml}$ for C. trifolii CT2 and to $1 \times 10^{5}$ spores/ml for $P$. medicaginis CT1 with sterile distilled water. The fungal strains were maintained through sequential passages in plants.

\section{Plant material}

The Medicago sativa plants used were the regenerative clone C2-3, kindly provided by Drs. B. McKersie and S. Bowley (Plant Biotechnology Division, Department of Plant Agriculture, University of Guelph, Canada), and the regenerative clone 432-19-17, previously isolated in our laboratory.

\section{Bacterial and plant RNA Isolation and CDNA synthesis}

Total bacterial (E. coli) and plant tissues (roots, steam, leaflets) RNA was extracted by using an RNeasy Mini Kit (Cat. \# 74106, Qiagen) following the manufactures' instructions. Samples of $2 \mu \mathrm{g}$ total RNA isolated from bacterial cells or plant tissues were reverse-transcribed in a $25 \mu \mathrm{l}$ reaction using MMLV-RT (Cat. \# M1701, Promega). For PCR amplification in bacteria and plants, $1 \mu \mathrm{l}$ of RT reaction was used. The PCR reactions were carried out in $25 \mu \mathrm{l}$ with $0.5 \mu \mathrm{M}$ of each primer [27], using Taq polymerase (Cat\#. 11615010, Invitrogen) following the manufactures' instructions.

\section{MsSN1 plasmid construction}

The MsSN1 cDNA (GenBank accession number JQ809686) was isolated using primers p1 FW and p2 RV (Additional file 1 ) designed against the $5^{\prime}$ and $3^{\prime}$ untranslated regions (UTR) of the putative SN1 gene (GenBank accession number XM_003589066, MTR_1g018640) from Medicago truncatula. Full-length cDNA was amplified by PCR and this fragment was cloned into a pCR2.1TOPO vector (Cat. \# K4500-01, Invitrogen). The pTOPO-MsSN1 plasmid was digested with Not I (Cat. \# R6431, Promega), treated with Klenow, and religated to destroy the polylinker Not I site. The resulting plasmid was named pTOPO-NotIMsSN1. The sequencing reactions of pTOPO-NotI-MsSN1 were performed at INTA-Argentina (www.inta.gov.ar). 
The cDNA sequence was named MsSN1 (Medicago sativa snakin-1). To produce recombinant bacteria expressing $M s S N 1$, plasmid pSJ33-MsSN1 carrying MsSN1 was constructed by subcloning the 0.5-kb EcoRI (Cat. \# R6011, Promega) fragment from pCR2.1TOPO-MsSN1 into pSJ33 [28], and afterward introduced in Escherichia coli for heterologous expression of MsSN1. To produce transgenic alfalfa lines overexpressing MsSN1, pCR2.1TOPO-NotIMsSN1 was digested with KpnI (Cat. \# R6341, Promega) and XbaI (Cat. \# R6181, Promega), and the MsSN1 restriction fragment was cloned into pKANNIBAL vector (GenBank accession number AJ311873). The resulting plasmid was digested with NotI, and the 35SMsSN1 restriction fragment was cloned into pART27 binary vector [29]. The resulting recombinant binary vector containing the MsSN1 cDNA with its signal peptide under the CaMV 35S promoter was named pART-35S::MsSN1.

\section{Bioinformatic analysis of MsSN1}

MsSN1 sequence of Medicago sativa (AFE82743), a peptide composed of 91 amino acids, was used as query to search against all available complete eukaryotic genome databases in NCBI with protein annotation in GenBank. The cut-off to obtain candidate orthologs was $20 \%$ of amino acid identity (Additional file 2). Sequences were searched by using BLASTP tools in NCBI and PLAZA databases (http://www.ncbi.nlm.nih.gov/blast; http://bio informatics.psb.ugent.be/plaza). Protein identity calculations were performed using MatGAT v2.02 [30]. Evolutionary analysis was conducted by using MEGA version 5.0 [31]. Protein sequences were aligned using the ClustalW program. Phylogenetic trees were constructed using the neighbor-joining method with genetic distances computed using the pairwise deletion model and bootstrap analysis of 500 values and root on midpoint (i.e. midpoint of the longest pathway between two clusters of sequences). In silico analysis of conserved motifs in putative snakin/ GASA proteins, Pfam domains and signal peptides were predicted by using Pfam and Signal-3 L with default parameters, respectively $[32,33]$.

\section{DNA extraction and sequence analysis of fungal strains}

Fungal DNA was extracted as previously described by Moller [34] with modifications suggested by Dr. E.W. Boehm (http://www.eboehm.com/). Briefly, $100 \mathrm{mg}$ of fungal mycelia was scraped from 10-day-old PDA cultures, ground in a $1.5 \mathrm{ml}$ tube with micropestle by adding $500 \mu \mathrm{l}$ of Lysis Buffer (100 mM Tris $\mathrm{pH} 8,10 \mathrm{mM}$ EDTA, 2\% SDS, 1\% $\beta$-Mercaptoethanol, $100 \mu \mathrm{g} / \mathrm{ml}$ proteinase K). Lysate was incubated at $60^{\circ} \mathrm{C}$ for $60 \mathrm{~min}$. Subsequently, $5 \mathrm{M} \mathrm{NaCl}$ was added to a final concentration of $1.4 \mathrm{M}$ and mixed before adding $0.1 \mathrm{vol}$ of CTAB $10 \%(\mathrm{w} / \mathrm{v})$. The mixture was incubated at $65^{\circ} \mathrm{C}$ for $10 \mathrm{~min}$. DNA was extracted by adding an equal volume of chloroform:isoamyl alcohol (24:1), incubating for $30 \mathrm{~min}$ at $0^{\circ} \mathrm{C}$ and centrifuging at $14,000 \times \mathrm{g}$ for $10 \mathrm{~min}$ at $4^{\circ} \mathrm{C}$. The aqueous phase was mixed with $0.5 \mathrm{vol}$ of $5 \mathrm{M}$ ammonium acetate, incubated at $0^{\circ} \mathrm{C}$ for $60 \mathrm{~min}$ and centrifuged at $14,000 \times \mathrm{g}$ for $1 \mathrm{~min}$. DNA was precipitated from the supernatant by adding $0.55 \mathrm{vol}$ of isopropanol, centrifuged at $14,000 \times \mathrm{g}$ for $10 \mathrm{~min}$ and washed twice with $70 \%$ ethanol. DNA pellet was air-dried and resuspended in $50 \mu \mathrm{l}$ of TE (10 mM Tris pH 8.0; 1 mM EDTA pH 8.0). The internal transcribed spacer regions $1 \& 2$ and 5.8S nrDNA (ITS) and partial sequences of TUB genes were amplified and sequenced by Macrogen Inc. (Korea) service (http:// www.macrogen.com/) using the primer pairs ITS-1FW and ITS-4RV and Btub2FW and Btub4RV, respectively (Additional file 1). The nucleotide sequences obtained here were deposited in the EMBL Nucleotide Sequence Database, accession numbers: KF846005 for $C$. trifolii TUB, KF846006 for P. medicaginis TUB, KF846009 for $C$. trifolii ITS and KF846010 for P. medicaginis ITS.

\section{In vitro antimicrobial activity assays}

Escherichia coli recombinant strains containing the pSJ33 empty vector or pSJ33-MsSN1 were grown overnight at $30^{\circ} \mathrm{C}$ with shaking ( $250 \mathrm{rpm}$ ) in LB medium supplemented with $1 \mathrm{mM}$ isopropyl- $\beta$-D-thiogalactopyranoside in 250$\mathrm{ml}$ Erlenmeyer flasks containing $50 \mathrm{ml}$ of medium. Samples of $25 \mathrm{ml}$ of culture broth (O.D: 0.8 ) were centrifuged at $5,000 \times \mathrm{g}$ at $4^{\circ} \mathrm{C}$ for $10 \mathrm{~min}$. The pellets were washed three times with physiological solution $(0.9 \% \mathrm{NaCl})$. Crude cell lysates were achieved by four consecutive cycles of freezing in liquid nitrogen followed by thawing at $37^{\circ} \mathrm{C}$. After centrifugation at $14,000 \times \mathrm{g}$ at $4^{\circ} \mathrm{C}$ for $20 \mathrm{~min}$, the supernatant was resuspended in $400 \mu$ lof physiological solution. For the analysis of MsSN1 expression in E. coli, total bacterial RNA was extracted by using the RNeasy Mini kit and treated with DNaseI (Cat. \# M6101, Promega). cDNA was obtained using random hexamers (Cat. \# B070-40, Promega) and AMV Reverse Transcriptase (Cat. \# M9004, Promega). For PCR amplification, $1 \mu \mathrm{l}$ of $\mathrm{RT}$ reaction was used. The PCR reactions were carried out in $25 \mu \mathrm{l}$ with $0.5 \mu \mathrm{M}$ of each primer according to Setten [27]. PCR conditions comprised: 1 cycle at $94^{\circ} \mathrm{C}$ for $3 \mathrm{~min}$, 34 cycles of $94^{\circ} \mathrm{C}$ for $45 \mathrm{~s}, 56^{\circ} \mathrm{C}$ for $1 \mathrm{~min}$ and $72^{\circ} \mathrm{C}$ for $1 \mathrm{~min}$. The expression of $M s S N 1$ was analyzed using primers p3 FW and p4 RV which amplify the complete open reading frame (Additional file 1).

The disk inhibition assays were evaluated as described by Ayub [35], with very slight modifications. Cultures were performed in 125-ml Erlenmeyer flasks containing $25 \mathrm{ml}$ of TY medium [36] or LB medium for rhizobia or Pseudomonas and Agrobacterium, respectively. Bacteria were incubated overnight at $28^{\circ} \mathrm{C}$ with shaking $(250 \mathrm{rpm})$. Sterile Whatman No. 1 filter disks $(5 \mathrm{~mm})$ impregnated with $5 \mu \mathrm{l}$ of $M s S N 1$-free (E. coli pSJ33) or MsSN1 (E. coli 
pSJ33-MsSN1) extracts were placed on top of bacteriaseeded plates. Zones of inhibition were measured after incubation at $28^{\circ} \mathrm{C}$ for $24 \mathrm{~h}$. The antifungal activities of the MsSN1 extract were determined according to Kovalskaya [12] by counting germinating and non-germinating fungal spores. The fungal spores of Phoma medicaginis var. medicaginis CBS 316.90 from CBS-KNAW Fungal Biodiversity Center (www.cbs.knaw.nl/Collections) were prepared in PDB. For the inhibition assays, spore suspensions of $1 \times 10^{5}$ spores/ml were used. Each antifungal assay was performed in triplicate.

\section{Plant transformation}

The recombinant binary vector pART-35S::MsSN1 was introduced into Agrobacterium tumefaciens LBA 4404 by electroporation, by using the procedure described by Shen \& Forde [37]. Petioles of alfalfa clone C2-3 were transformed with pART-35S::MsSN1 via A. tumefaciens and cultured in vitro as described by D'Halluin [38], with slight modifications (Additional file 3). Petiole tissues were decontaminated by immersing in $70 \%$ ethanol for $1 \mathrm{~min}$ and then in $2 \%$ sodium hypochlorite for $20 \mathrm{~min}$. The petioles were washed 3 times in sterile distilled water. Explants previously injured with a scalpel were inoculated with a bacterial culture for 2 minutes $\left(\mathrm{OD}_{600 \mathrm{~mm}}=\right.$ 0.5-0.8), and then dried in Whatman filter paper and transferred onto a solid co-cultivation SHK medium [3\% sucrose, $0.435 \% \mathrm{KSO}_{4}, 2 \mathrm{mg} / \mathrm{l}$ 2.4-D, $0.2 \mathrm{mg} / \mathrm{l}$ kinetine, $6.5 \mathrm{~g} / \mathrm{l}$ agar, 20\% SHK stock solution (w/v) pH:5.8 (300 mg/l NH $\mathrm{H}_{2} \mathrm{PO}_{4}, 2.5 \% \mathrm{KNO}_{3}, 200 \mathrm{mg} / \mathrm{l} \mathrm{CaCl} 2.2 \mathrm{H}_{2} \mathrm{O}$, $400 \mathrm{mg} / \mathrm{l} \mathrm{MgSO} .7 \mathrm{H}_{2} \mathrm{O}, 4.3 \% \mathrm{~K}_{2} \mathrm{SO}_{4}, 1 \mathrm{mg} / \mathrm{l} \mathrm{KI}, 5 \mathrm{mg} / \mathrm{l}$ $\mathrm{H}_{3} \mathrm{BO}_{3}, 10 \mathrm{mg} / \mathrm{l} \mathrm{MnSO}{ }_{4} \cdot \mathrm{H}_{2} \mathrm{O}, 1 \mathrm{mg} / \mathrm{l} \mathrm{ZnSO} \cdot \mathrm{H}_{2} \mathrm{O}, 1 \mathrm{mg} / \mathrm{l}$ $\mathrm{Na}_{2} \mathrm{MoO}_{4} \cdot 2 \mathrm{H}_{2} \mathrm{O}, 1 \mathrm{mg} / \mathrm{l} \mathrm{CuSO}_{4} \cdot 5 \mathrm{H}_{2} \mathrm{O}, 0.1 \mathrm{mg} / \mathrm{l} \mathrm{CoCl}{ }_{2}$. $6 \mathrm{H}_{2} \mathrm{O}, 26.29 \mathrm{mg} / \mathrm{l} \mathrm{NaFeEDTA} . \mathrm{H}_{2} \mathrm{O}, 288 \mathrm{mg} / \mathrm{l}$ proline, $53 \mathrm{mg} / \mathrm{l}$ thioproline, $200 \mathrm{mg} / \mathrm{l}$ myo-inositol, $5 \mathrm{mg} / \mathrm{l}$ nicotinic acid, $0.5 \mathrm{mg} / \mathrm{l}$ pyridoxine, $5 \mathrm{mg} / \mathrm{l}$ thiamine)] containing $100 \mu \mathrm{M}$ acetosyringone for 2 days at $25^{\circ} \mathrm{C}$ in the dark. The explants were then washed with $0.5 \mathrm{~g} / \mathrm{l}$ cefotaxime supplemented with distilled water and transferred to selection/induction medium SHK containing 25 mg/l kanamycin and $400 \mathrm{mg} / \mathrm{l}$ cefotaxime with routine transfers to fresh medium every 2 weeks, at $25^{\circ} \mathrm{C}$ and $16 \mathrm{~h}$ light (100 $\mu$ moles $\mathrm{m}^{-2} \mathrm{~s}^{-1}$ ). Somatic embryos were obtained three months later and then transferred to MS rooting medium, composed of Murashige and Skoog Basal Medium (Cat. \# M5519, Sigma) diluted 1:2 with water. Transgenic plants were obtained about 6 months after callus induction. The regenerated plantlets were transferred to the greenhouse once they were well rooted. All plants were grown in a greenhouse at $25-20^{\circ} \mathrm{C}$ day/night temperature and watered daily. Alfalfa transgenic events (named S1, S2 and S3) were propagated by crossing with clone 432-19-17 and by cuttings to increase the number of plants available for biochemical, physiological, and genetic analysis.

\section{Identification of transgenic plants}

DNA was isolated from leaf tissue with the DNeasy plant mini kit (Cat. \# 69104, Qiagen). Transgenic plants were first identified by PCR with primers p5 FW and p6 RV (Additional file 1), designed against the $35 \mathrm{~S}$ promoter and SN1 regions of recombinant binary vector. The expression of the transgene was corroborated by RT-PCR, using primers $\mathrm{p} 7 \mathrm{FW}$ and $\mathrm{p} 4 \mathrm{RV}$, designed against the pCR2-1-TOPO-MCS-derived 5' UTR region and the 5' UTR of the MsSN1 gene (Additional file 1). All PCR reactions were performed with Taq (Cat. \# 11615010, Invitrogen).

For Southern hybridization analysis, genomic DNA was isolated from leaf tissues of greenhouse-grown plants using the DNeasy Plant Maxi kit (Cat. \# 68161, Qiagen) following the manufacture's indications. DNA was digested with the KpnI restriction enzyme, which cleaves the construct only once. Then, $20 \mu \mathrm{g}$ of DNA from each sample was digested overnight and blotted after separation on $1 \%(\mathrm{w} / \mathrm{v})$ agarose gel $1 \times$ TAE. The DNA fragments in gels were transferred to a positively charged Nylon membrane (Cat. \# 11209272001, Roche). Nylon membranes were crosslinked and then used for hybridization with a DIG-labeled probe. Prehybridization and hybridization was carried out according to the manufacturer's instructions. The hybridization probe MsSN1digoxigenin-labeled DNA was generated by PCR by using the PCR DIG probe synthesis kit (Cat. \# 11573152910, Roche), using primers p8 FW and p9 RV and then used as a probe (Additional file 1). PCR amplification was performed under standard conditions ( $25 \mu \mathrm{l}$ volume using $0.8 \mu \mathrm{M}$ of each primer, $1 \mathrm{X}$ PCR buffer, $0.2 \mathrm{mM}$ each dNTP, $2 \mathrm{mM} \mathrm{MgCl}_{2}$ and $20 \mathrm{ng}$ of template) with a program of 34 cycles of $94^{\circ} \mathrm{C}$ for $1 \mathrm{~min}, 50^{\circ} \mathrm{C}$ for $30 \mathrm{~s}$ and $72^{\circ} \mathrm{C}$ for $2.5 \mathrm{~min}$ and a final cycle of $72^{\circ} \mathrm{C}$ for $10 \mathrm{~min}$.

\section{Real-time quantitative RT-PCR (RT-qPCR)}

For RT-qPCR, PCR amplification was performed with $5 \mu \mathrm{l}$ of RT (1:5 diluted) per reaction, by using $1 \mathrm{U}$ iQ SYBR green Supermix (Cat. \# 170-8880, Bio-Rad) and $0.2 \mathrm{mM}$ primers, with the iCycler iQ system. Primers for the realtime qPCR were p10 FW and p11 RV (Additional file 1). qPCR conditions comprised: 1 cycle at $94^{\circ} \mathrm{C}$ for $5 \mathrm{~min}$, 34 cycles of $94^{\circ} \mathrm{C}$ for $45 \mathrm{~s}, 59.1^{\circ} \mathrm{C}$ for $30 \mathrm{~s}$, and $72^{\circ} \mathrm{C}$ for $30 \mathrm{~s}$. At each cycle, accumulation of PCR products was detected. The amplification fragment was sequenced and found to be identical (100\% nucleotide identity) to the MsSN1 gene. The expression level of MsSN1 was normalized using aspartate aminotransferase (ATT) (AAB46610) as a housekeeping gene, using primers p12 FW and p13 RV (Additional file 1). The efficiency of primer binding was determined by linear regression by plotting the cycle threshold value versus the log of the cDNA dilution [39]. RT-qPCR experiments were performed two or three times 
with independent RNA samples (biological replicates). For each biological replicate the $\mathrm{qPCR}$ reactions were carried out in duplicate.

\section{Bioassays. In vitro challenges}

Assays were performed in healthy 15 day-old nonfumigated leaflets. Leaflets were decontaminated washing them in flasks with sterile water with Tween-20 (0.01\%) for $10 \mathrm{~min}$. After three washes with sterile water, the leaflets were transferred to a $5 \%$ hypochlorite solution for $5 \mathrm{~min}$. Finally, leaflets were washed three times with sterile water and transferred to agar-water petri dishes. Plates were maintained in growth chambers programmed for $16 \mathrm{~h}$ light at $23^{\circ} \mathrm{C}$ and $8 \mathrm{~h}$ dark at $20^{\circ} \mathrm{C}$. Leaflets were inoculated by putting $5 \mu \mathrm{l}$ of $P$. medicaginis CT1 or C. trifolii CT2 spore solution per leaflet. Infection evolution was observed and documented by photos and the following damage score was generated to quantify injuries: 1 . Healthy leaflet, 2. Countable injuries, 3. Uncountable injuries, 4. Chlorosis, 5. Completely damaged.

\section{Bioassays. In vivo challenges}

Alfalfa transgenic seeds were obtained by crossing transgenic plants S1, S2 and S3 with 432-19-17 genotype plants. Transgenic and wild type seeds were treated with sulfuric acid for 10 minutes, washed three times with sterile water and placed in petri dishes with $1 \%$ agar water at $16 \mathrm{~h}$ of light $\left(100 \mu\right.$ moles $\left./ \mathrm{m}^{2} \mathrm{~s}\right)$ and $25^{\circ} \mathrm{C}$. Germinated plantlets were transferred to MS 0.5X flasks and incubated at $25^{\circ} \mathrm{C}$ with $16 \mathrm{~h}$ photoperiod for 1 month, after which plants were transferred to 1:1 vermiculite:perlite and maintained in magenta vessels (SIGMA) to conserve the humidity. Two-month-old plants were inoculated with P. medicaginis CT1 by spraying spore suspension to all aerial tissues. Percentage of diseased leaflet was analyzed 30-day post-inoculation and the number of plants with regrowth and the percentage of highly defoliated plants was counted 60-days post-inoculation. As an additional severity parameter of plant disease, the percentage of vigor affected plants (i.e. with visual signs of turgidity loss compared with non-inoculated plants) was estimated. All experiments were carried out with at least 10 independent plants per treatment and with at least 5 non inoculated wild type plants used as control.

\section{Evaluation of bacterial root colonization}

For the symbiosis assay, wild type and transgenic alfalfa seedlings were grown in $100 \%$ vermiculite and daily irrigated with the minimal medium called "INTA13 without nitrogen" [27]. 10-days-old plants were inoculated with an early stationary-phase culture of rhizobial suspension (Sinorhizobium meliloti BL225C). After a month, the plants were harvested and the number of pink nodules was analyzed. Non-inoculated plants were used as controls.
Three replicates were analyzed for each treatment. The $P$. fluorescens Pf-5 colonization assay was evaluated according to Sanchez [40], with two slight modifications: alfalfa was grown in INTA13 supplemented with $\mathrm{Ca}\left(\mathrm{NO}_{3}\right)_{2}$ [27] and $0.5 \mathrm{NE} 2$ medium plus sodium octanoate $(0.25 \% \mathrm{w} / \mathrm{v})$ was used to estimate the colony forming units [28].

\section{Statistical analysis}

Biological measurements were repeated at least three times with at least 10 different plants. Significant differences between treatments were calculated using Student's t-test. qPCR experiments were independently performed three times, with comparable results. The three PCR reactions were carried out in duplicate. Significant differences were calculated using ANOVA followed by Tukey test.

\section{Results and discussion}

\section{Identification and evolutionary analysis of MsSN1}

To analyze the evolution and function of MsSN1, a 276bp cDNA fragment was isolated from roots by RT-PCR, using specific primers designed for a putative snakin-1 peptide predicted from the genome of the model legume Medicago truncatula (MtSN1, MTR_1g018640). The PCR product was cloned into a pCR2.1TOPO vector and sequenced (JQ517286). This cDNA fragment shares 98\% identity with the putative snakin-1 peptide from Medicago truncatula (XP_003589114), hence it was named MsSN1 (Medicago sativa snakin-1). Like potato snakin-1 peptide (StSN1), MsSN1 has a putative signal peptide of 25 amino acids and possesses a snakin/GASA domain (Pfam02704) containing 12 cysteine residues in conserved positions within a conserved C-terminal region (Figure 1).

To perform a phylogenetic analysis of SN1, the evolutionary study was restricted to well-characterized sequenced species of plants using proteins with high amino acid identity (>20\%). Using this strict criterion, complete congruence (i.e. same topology) between SN1 and vascular plant trees was observed (Figure 2), suggesting that plant SN1 was acquired by vertical transfer [41]. Since our phylogenetic analysis of SN1 was consistent with rRNA data, orthologous SN1 assignment is possible in any vascular plant. Thus, our evolutionary study suggests that MsSN1 from Medicago sativa (JQ517286) presented in this work is indeed the ortholog of the StSN1 from Solanum tuberosum (Q948Z4), the gibberellinstimulated transcript 1 (OsGASR1) from Oryza sativa (AB192574) and the GASA7 from Arabidopsis thaliana (AEC06348) previously described $[3,42,43]$, thus offering a starting point for experimental data integration to indepth understanding of SN1 function in plants. It is important to note that orthologous identification of snakin-like peptides could not be predicted by comparing their amino acid identity with snakin/GASA-related proteins such as Arabidopsis GASAs (Additional file 4). 


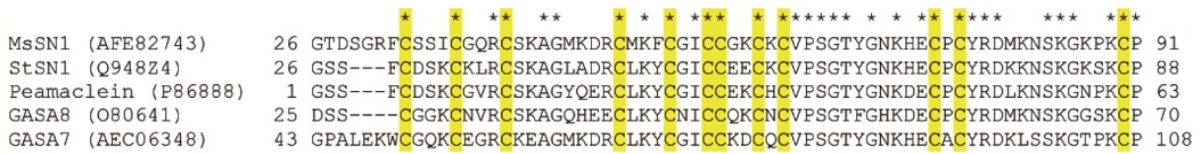

Figure 1 Alignment of residues 26-91 of MsSN1 from alfalfa with the corresponding regions of snakin/GASA proteins from potato (StSN1), Arabidopsis (GASA7 and GASA8) and Peach (Peamaclein) revealing 12 cysteine residues in conserved positions within a conserved C-terminal region. These cysteine residues are shown in yellow.

Therefore, assessment of the correct orthology of snakin/ GASA genes requires rigorous phylogenetic analysis.

In order to support the vertical origin of higher plant SN1, the SN1 gene is present in the primitive vascular plant Selaginella moellendorffii (Figure 2). In addition, an exhaustive phylogenetic analysis of proteins within genome databases failed to find orthologous genes of SN1 in the ancestral moss Physcomitrella patens, and in green algae species belonging to the phylum Chorophyta such as Ostreococcus lucimarinus, Micromonas sp. RCC299, Volvox carteri and Chlamydomonas reinhardtii. In agreement with this finding, proteins containing the snakin/GASA domain are widely distributed in land plants but completely absent in moss and green algae (data not shown), suggesting that $S N 1$ is an ancestral gene that appeared in the vascular lineage after the vascular/bryophyte separation. This is not surprising considering that the pioneering ancestors of land plants that dominated terrestrial environments had to confront dramatic stresses, including the infection produced by an extreme diversity of microbial soil communities, selecting a number of genetic innovations [44]. Therefore, the emergence of SN1 could be an adaptation of ancestral plants to land.

\section{Analysis of the in vitro antimicrobial activity of MsSN1}

Regarding the in vitro characterization of MsSN1 antimicrobial activity, the MsSN1 gene was expressed in
E. coli. The expression of MsSN1 in the transformed $E$. coli cells was confirmed by RT-PCR analysis (Additional file 5). The antimicrobial activity of $M s S N 1$-free or MsSN1 extracts was tested against the bacterial and fungal alfalfa pathogens Agrobacterium tumefaciens LBA4404 and Phoma medicaginis var. medicaginis CBS 316.90, respectively. Antimicrobial activity of the MsSN1-free extract was undetectable, whereas the MsSN1 extract showed a high inhibitory activity against bacterial growth (Figure 3A-B) and fungal spore germination (Figure 3C-F). As previously described for other members of snakin/ GASA peptides [3,4], the antimicrobial activity of MsSN1 against organisms belonging to different domains, at least Bacteria and Eukarya, is congruent with its function as a component of the non-specific immune system of plants.

\section{Analysis of MsSN1 expression}

The expression pattern of the MsSN1 gene was analyzed by RT-PCR, to explore the function of $M s S N 1$ in wild type alfalfa plants. MsSN1 expression was detected in all tissues analyzed, including roots, stems, leaves and young floral buds (Additional file 6). RT-qPCR assays were performed to evaluate whether the expression levels of MsSN1 is modified by exposure to microorganisms. MsSN1 transcript levels were about two-fold higher in leaves than in roots when plants were grown under control conditions (Figure 4). Interestingly, MsSN1 levels did not change in response to biotic stimuli, such as the

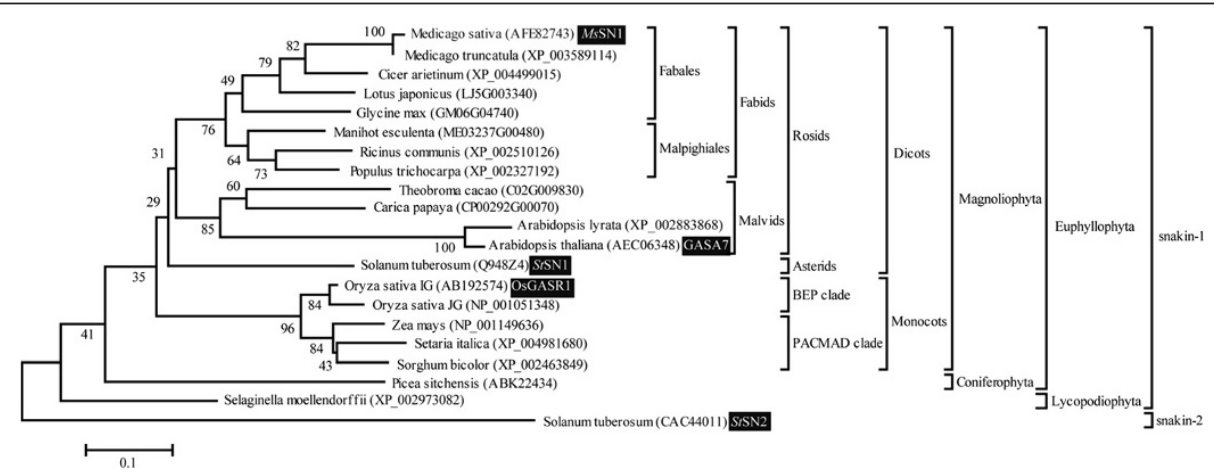

Figure 2 Phylogenetic tree of plant SN1 protein sequences using the neighbor-joining method and root on midpoint. Bootstrap percentages are indicated at the branch points. The current classification of plants is found on the right. Tree topology obtained using $\mathrm{NJ}$ method, Minimum evolution and Maximum parsimony methods were identical. The MsSN1 peptide characterized in this work and other snakin/ GASA peptides described in previous experimental studies are boxed. 

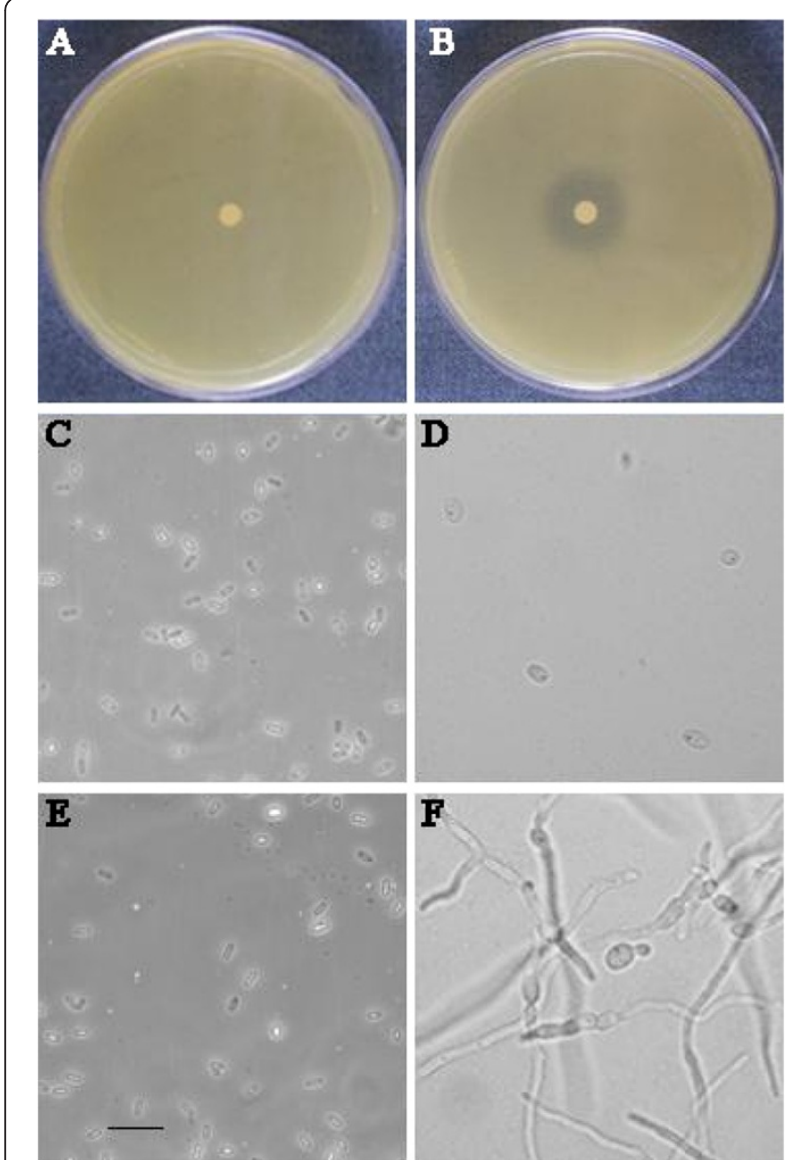

Figure 3 Analysis of the in vitro antimicrobial activity of MsSN1. Agrobacterium growth $(\mathbf{A}-\mathbf{B})$ and Phoma spore germination $\left(1 \times 10^{5}\right.$ spores $/ \mathrm{ml}$ ) (C-F) inhibition assays using MsSN1-free (A, C and D) or MsSN1 extracts (B, E and F). Spore germination was examined immediately (C and E) and after $16 \mathrm{~h}$ ( $\mathbf{D}$ and $\mathbf{F}$ ) of incubation with the extracts. Bar $=50 \mu \mathrm{m}$.

pathogenic bacterium A. tumefaciens LBA4404, the symbiotic strain Sinorhizobium meliloti BL225C and the freeliving strain Pseudomonas fluorescens Pf-5 (Figure 4). In concordance with the characterization of StSN1 expression in potato [3], the expression pattern of MsSN1 suggests that $S N 1$ is a component of the constitutive defense barrier.

\section{Molecular characterization of transgenic alfalfa plants overexpressing MsSN1}

In order to investigate the antimicrobial activity of MsSN1 against alfalfa fungal pathogens, transgenic alfalfa plants were generated. The MsSN1 gene was placed into a constitutive expression cassette under the control of the CaMV $35 \mathrm{~S}$ promoter (Figure 5A), and introduced in alfalfa plants of the regenerable clone $\mathrm{C} 2-3$ by Agrobacterium tumefaciens-mediated transformation (Additional file 3). PCR assays (Additional file 7A) and Southern Blot analyses (Additional file 7B) were used to identify three

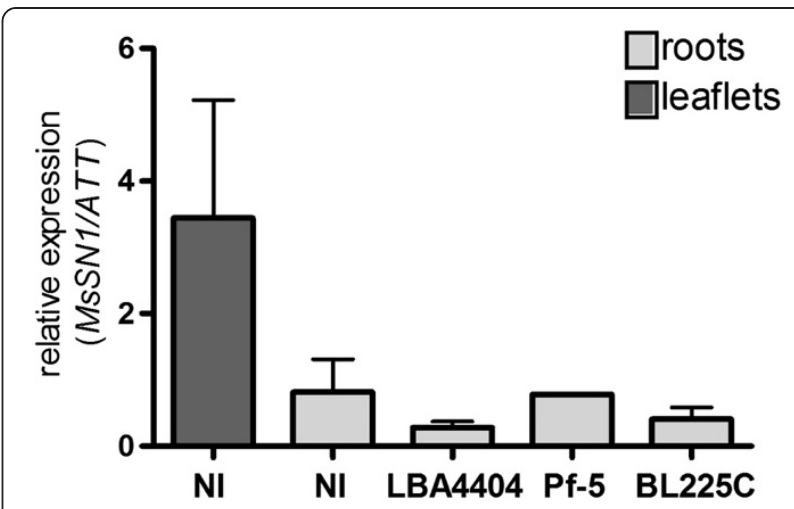

Figure 4 Quantitative analysis of the expression of the MsSN1 gene in wild type alfalfa plants under microbe stress conditions. Real-time RT-PCR studies for MSSN1 expression in non-inoculated leaves and roots (NI) or in roots exposed to Agrobacterium tumefaciens LBA4404, Pseudomonas fluorescens Pf-5 and Sinorhizobium meliloti BL225C for 24 hs.

independent transgenic alfalfa lines, named S1, S2 and S3, harboring the CaMV35S:MsSN1 construct. Evolutionary analyses showed that Medicago truncatula and Lotus japonicus genomes have only one locus per genome of the SN1 gene, MTR_1g018640 and LJ5G003340, respectively. Consistent with this, as well as with the remarkably conserved genome structure among legumes [45] and the tetrasomic inheritance and outcrossing nature of alfalfa [46], the non-transformed alfalfa plants showed the presence of three copies, probably alleles, of the MSSN1 gene (Additional file 7B). As expected, transgenic plants showed extra and differential bands on Southern blot hybridizations, suggesting the incorporation of the transgene in different regions of the alfalfa genome (Additional file 7B). The three events showed stable inheritance of the transgene (data not shown). Expression of the transgene was confirmed by RT-PCR analyses using specific primers designed for the chimeric 5' UTR (Additional file 7C). Individual lines were also analyzed by RT-qPCR assays for MsSN1 expression. Transgenic lines showed that the expression level of total MsSN1 was 100-fold higher than wild type endogenous expression (Figure 5B), suggesting that the three transgenic lines were good candidates to evaluate the effects of overexpressing MsSN1.

Similar to transgenic lines from potato, wheat and tomato [6,10,11], overexpression of MsSN1 did not appear to affect negatively the general phenotype in transgenic alfalfa plants, e.g. there was no reduction in the plant vigor in transgenic plants compared to wild type plants (Additional file 8). Therefore, transgenic alfalfa plants appear to be a suitable platform to study the role and biotechnological potential of MsSN1. Unfortunately, no MsSN1 reduced expression or silenced alfalfa plants were obtained (data not shown). Similar results were 
A

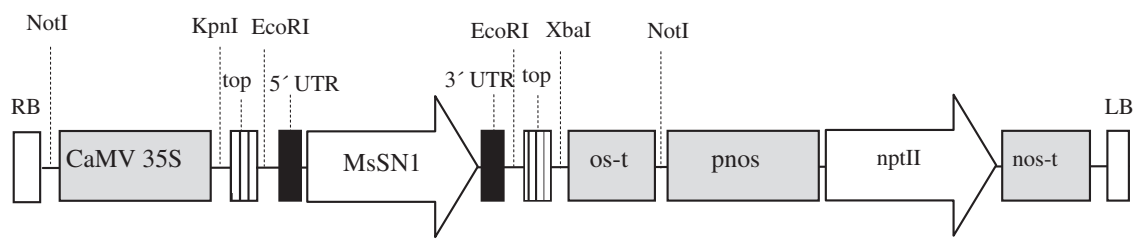

B

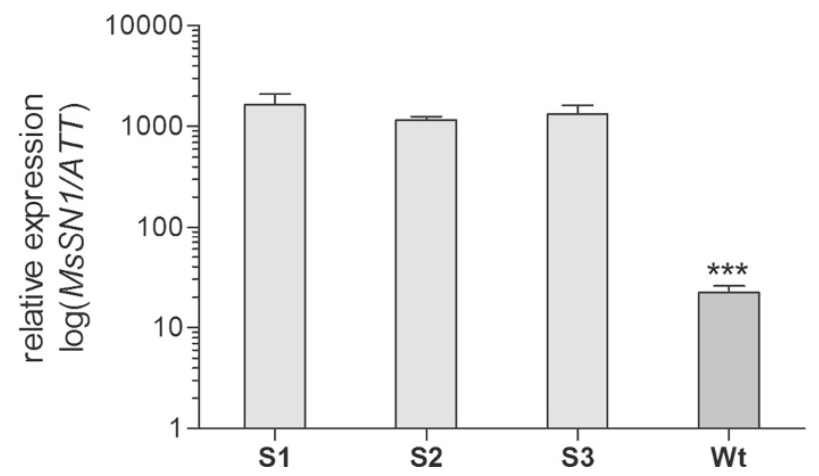

Figure 5 Characterization of transgenic alfalfa lines overexpressing MsSN1. (A) Schematic representation of the T-DNA region of binary vector PART-35S::MsSN1 containing the MSSN1 gene under the CaMV 35S promoter. Relevant restriction enzymes used in plasmid construction and Southern Blot analysis are shown. RB: right border; CaMV 35S: promoter; Topo: region derived from pCR2.1-TOPO vector; UTRs: untranslated regions derived from the native MSSN1 gene; os-t: octopine synthase terminator; pnos-nptll-nos-t: kanamycin cassette (where, pnos and nos-t are nopaline synthase promoter and terminator, respectively); LB: left border. (B) Real-Time RT-PCR assays of alfalfa transgenic lines (S1-S3) and control untransformed plants $(w t)$. All values are log means $\pm \operatorname{SEM}(n=3)$. Asterisks indicate a statistically significant difference $\left(\right.$ Tukey: $\left.{ }^{* * *} p<0.001\right)$.

reported by Meiyalaghan [8] where the authors found no regenerant plants using antisense vectors expressing GSL1 (StSN1) and GSL2 (SN2) under their endogenous promoters regulation. These results probably indicate that MsSN1 silencing had detrimental effects on transformation or regeneration efficiency. In concordance with this observation, SN1 silencing drastically affects the cell division and primary metabolism of potato plants [14].

\section{Molecular characterization of two highly virulent alfalfa fungal strains}

Anthracnose and spring leaf spot, caused by the fungal pathogens Colletotrichum trifolii and Phoma medicaginis, respectively, are the most destructive infections of alfalfa worldwide. In the analysis of alfalfa resistance to these fungal diseases, there is usually a tradeoff between virulence and characterization of these pathogenic strains. Generally, long-term successive passages of archetype strains in vitro attenuate the virulence of these pathogens in vivo, while pathogens freshly isolated present a high virulence phenotype but their taxonomic position is commonly speculated based on disease symptoms or microscopy observations. In order to bypass this constraint, we used two highly virulent alfalfa fungal strains from alfalfa breeding programs, maintained through sequential plant infections and characterized through amplification, sequencing and phylogenetic analyses of conserved genes and intergenic regions. The evolutionary analyses of ITS region and TUB gene showed that these isolates belong to Colletotrichum and Phoma (Additional file 9). In fact, these DNA fragments from virulent strains (KF846005, KF846006, KF846009 and KF846010) share 100\% nucleotide identity with the ITS region and TUB genes from $C$. trifolii CBS 158.83 (KF178478 and KF178599) and P. medicaginis CBS 316.90 (GU237828 and GU237630), respectively. In accordance with these data, these isolates were named Colletotrichum trifolii strain CT2 and Phoma medicaginis strain CT1. Unlike the well-characterized fungal strains $C$. trifolii CBS 158.83 and P. medicaginis CBS 316.90, strains C. trifolii CT2 and P. medicaginis CT1 are highly virulent on alfalfa and infect a wide range of commercial cultivars as well as the alfalfa clones used in this work, C2-3 and 432-19-17. This confirms that the form of conservation of fungal pathogens is essential to maintain their alfalfa virulence, and therefore, to study the genetic basis of resistance to fungi in alfalfa.

\section{Antifungal in vitro activity of MsSN1-overexpressing transgenic plants}

As a first step to investigate the antifungal activity of transgenic alfalfa lines, in vitro challenge assays were performed. Detached leaflets were inoculated with a spore 
suspension of two virulent and molecularly characterized alfalfa fungal strains $P$. medicaginis CT1 and C. trifolii CT2 incubating the leaves in petri plates for 7 days (Figure 6A-B). Disease severity was estimated by visually scoring disease symptoms in infected leaflets as a percentage of leaflets showing disease lesions (Figure 6C). The three transgenic lines (S1- S3) showed significant lower percentage of diseased leaflets than wild type plants when challenged with both $P$. medicaginis CT1 (Figure 6A) and C. trifolii CT2 virulent strains (Figure 6B), suggesting an antimicrobial function of MsSN1 under biotic stress conditions. Moreover, this small-scale study could facilitate rapid visual screening of a large number of transgenic events (Figure 6D), saving time, reducing cost, and speeding up the introgression of this antimicrobial transgene into commercial varieties, especially in outcrossing species such as alfalfa [47].

\section{Antifungal in vivo activity of MsSN1-overexpressing transgenic plants}

The three transgenic alfalfa lines (S1-S3) were chosen for progeny analysis of their potentially enhanced biotic resistance. The clone 432-19-17 was used as a pollen donor in a sexual cross with the transgenic lines to avoid the common inbreeding depression of progeny from self-crossed alfalfa plants. The presence and expression of the transgene in leaves of the progeny plants were assayed by PCR and RT-qPCR analyses, respectively (data not shown). In vivo assays for antifungal activity against $P$. medicaginis CT1 were carried out spraying a spore solution to transgenic and wild type plants. Plant disease severity was estimated by evaluating agronomic parameters for two months. Wild type plants manifested all the symptoms of the disease $[48,49]$, including dark brown lesions on the stems, dark brown lesions on the leaflets that begin with specific dark color injuries, wilting leaves, chlorosis, and defoliation. Transgenic lines presented scarce symptoms and usually looked like control plants (data not shown).

Firstly, leaflet disease was estimated by visually scoring disease symptoms in infected plants. One month postinfection, the percentage of diseased leaflets was significantly lower in transgenic lines than in wild type plants (Figure 7A). Two months post-inoculation, disease severity was analyzed by evaluating the vigor of the plants, the number of plants with regrowth and the percentage of highly defoliated plants. Transgenic plants showed significantly higher levels of regrowth than wild type plants (Figure 7B, F and G). In fact, disease symptoms were present in wild type regrowth but not in transgenic plants (Figure 7G). Overexpression of MsSN1 in alfalfa improves plant vigor under fungal stress conditions (Figure 7C). In addition, wild type plants showed more defoliation than transgenic plants but the differences

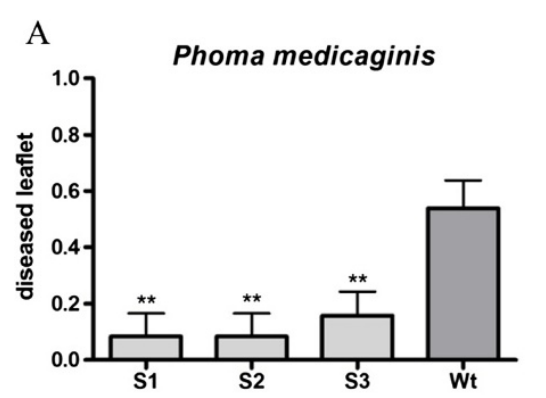

$\mathrm{C}$

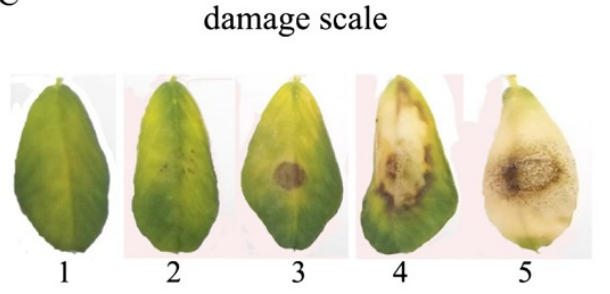

B Colletotrichum trifolii
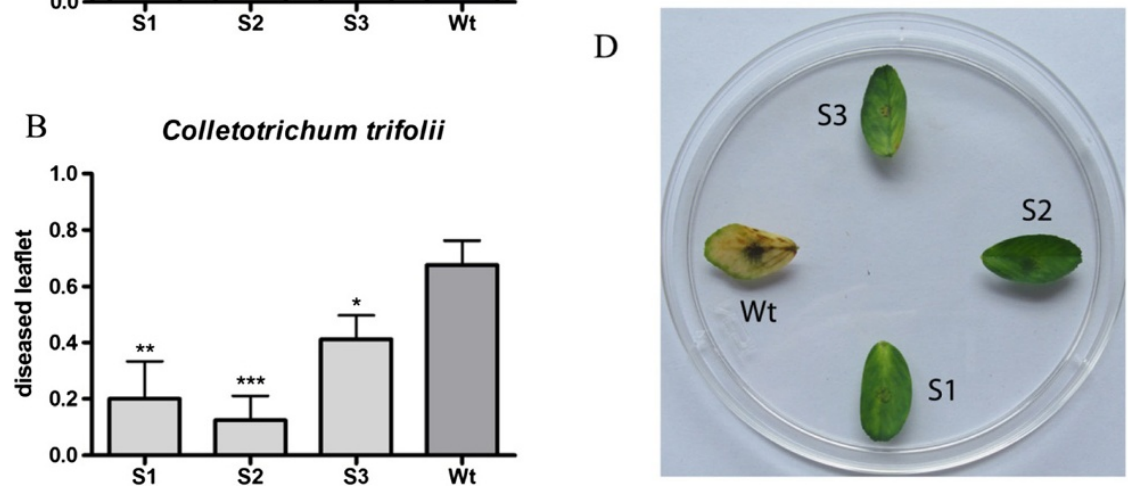

Figure 6 Antifungal in vitro activity of MsSN1 overexpressing transgenic plants. (A) Diseased leaflets related to leaflets inoculated with Phoma (\#diseased leaflet/\#total leaflet). (B) Diseased leaflets related to leaflets inoculated with Colletotrichum (\#diseased leaflet/\#total leaflet). (C) Damage score: 1. Healthy leaflet, 2. Countable injuries, 3. Uncountable injuries, 4. Chlorosis, 5. completely damaged. (D) Representative Phoma assay. Wt: wild type. S1-S3: MsSN1 transgenic plants. All values are log means \pm SEM $(n=10-30)$. Asterisks indicate a statistically significant difference (Turkey: ${ }^{*} p<0.5 ;{ }^{* *} p<0.01{ }^{* * *} p<0.001$ ). Leaflets were considered diseased when they showed symptoms 3,4 or 5 in the damage score. Disease severity was estimated from scoring 30 to 60 detached leaflets from three individual plants. 

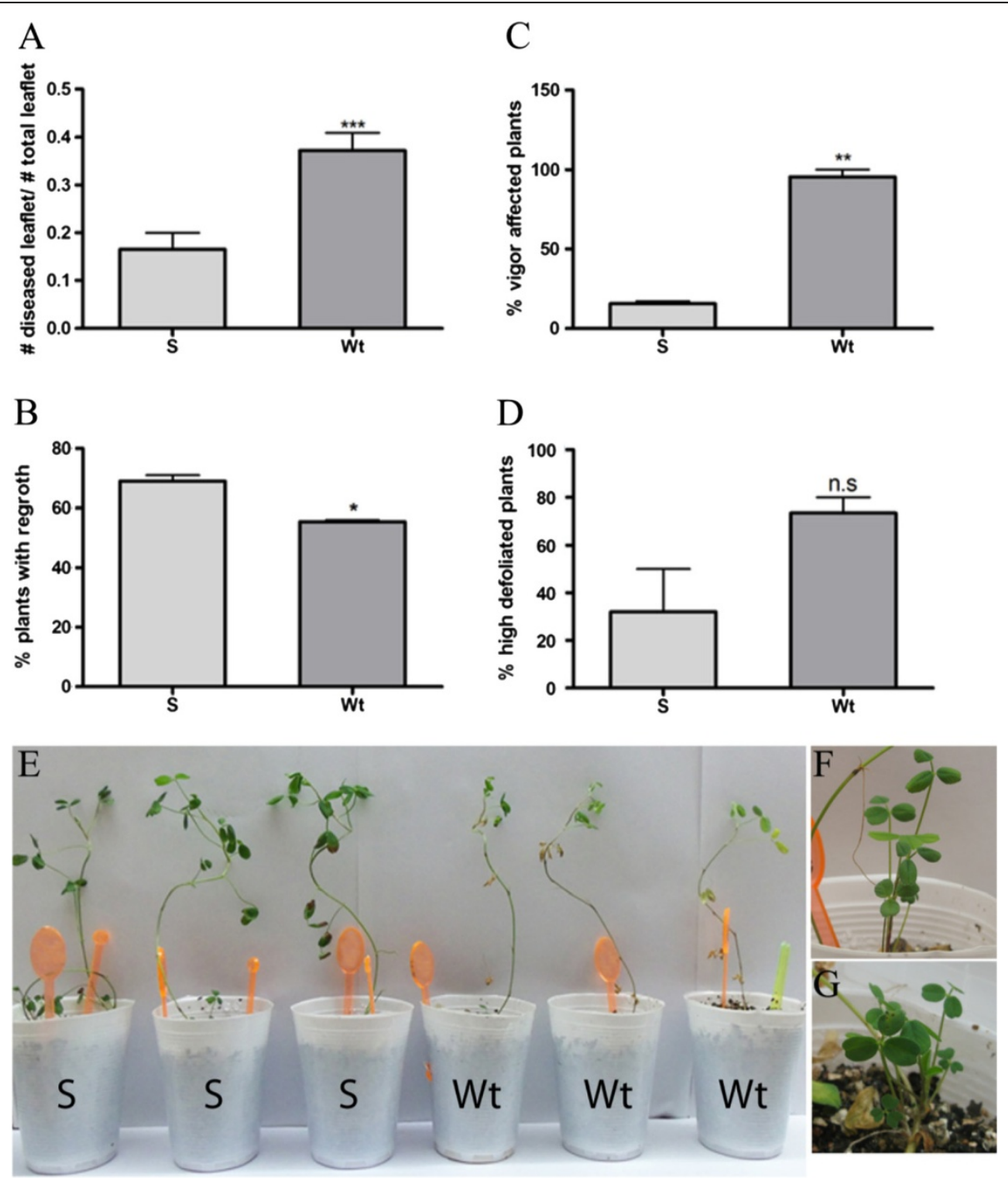

Figure 7 In vivo characterization of MsSN1 overexpressing transgenic plants for resistance to Phoma medicaginis CT1. (A) Number of diseased leaflets related to total number of leaflet in 30-day-old inoculated plants. (B) Percentage of two-month-old inoculated plants with regrowth. (C) Percentage of vigor affected two-month-old inoculated plants. (D) Percentage of highly defoliated two-month-old inoculated plants (highly defoliated $>3$ leaflets detached). (E) Representative photo comparing transgenic (S) with wild type (Wt) 30-day-old inoculated plants. (F) Detail of regrowth. (G) Detail of symptomatic regrowth. S: MsSN1-overexpressing plants. Wt: wild type. All values are means \pm SEM ( $n=15-25$ ). N.S: non-significant; ${ }^{*} \mathrm{p}<0.05 ;{ }^{* *} \mathrm{p}<0.01 ;{ }^{* *} \mathrm{p}<0.001$, t-test.

were not statistically significant (Figure 7D). Altogether, transgenic plants showed a better performance against Phoma infection than wild type plants, suggesting an antifungal activity of MsSN1 in vivo.

\section{Coevolution evidences of MsSN1 and rhizobia}

Similar to observations on other effector molecules of innate immunity [50], constitutive expression of MsSN1 could provide alfalfa a selective advantage over the pathogens during the early stages of microbial infection. However, it can also have adverse effects on beneficial microorganisms such as nitrogen-fixing symbiotic bacteria.
To investigate this apparent paradox, the in vitro antimicrobial activity of $M s \mathrm{SN} 1$ against nine rhizobacterial strains isolated from different legume plants and soil were analyzed. All rhizobacterias isolated from alfalfa nodules (Sinorhizobium meliloti BL225C, Sinorhizobium meliloti SM11 and Rhizobium sp. Or 191) showed no inhibition against the MsSN1 extract (Table 1). In contrast, the symbiotic nitrogen fixation strains isolated from other legume species, such as medick (Sinorhizobium medicae WSM419), soybean (Sinorhizobium fredii USDA 257 and Bradyrhizobium japonicum USDA110), bean (Rhizobium etli CFN 42) and Lotus spp. (Mesorhizobium loti MAFF303099), 
Table 1 Antimicrobial activity of alfalfa snakin-1 extract on rhizobial strains

\begin{tabular}{llll}
\hline Strain & Family & Source of the strain & Zone of inhibition $(\mathbf{m m})$ \\
\hline Bradyrhizobium japonicum USDA110 & Bradyrhizobiaceae & Soybean & $1.38 \pm 0.13$ \\
Mesorhizobium loti MAFF303099 & Phyllobacteriaceae & Lotus spp. & $1.50+0.30$ \\
Rhizobium sp. Or 191 & Rhizobiaceae & Alfalfa & 0 \\
Rhizobium etli CFN 42 & Rhizobiaceae & Bean & $1.18+0.09$ \\
Sinorhizobium meliloti BL225C & Rhizobiaceae & Alfalfa & 0 \\
Sinorhizobium meliloti SM11 & Rhizobiaceae & Alfalfa & 0 \\
Sinorhizobium medicae WSM419 & Rhizobiaceae & Medick & $1.26 \pm 0.06$ \\
Sinorhizobium fredii USDA 257 & Rhizobiaceae & Soybean & $1.13 \pm 0.13$ \\
\hline
\end{tabular}

were susceptible to the MsSN1extract (Table 1). These results suggest that alfalfa and their symbiotic bacteria may have coevolved.

There is a fine line between bacterial symbiosis and chronic infection. While one is beneficial the other is detrimental. Recent findings suggest that both share mechanisms for sidestepping host defenses [50]. Legumes evolved rapidly and shortly after their origin, and nodulation most likely evolved several times during their divergence [51]. These plants have symbiotic nitrogenfixing bacteria living in root nodule compartments that also contain antimicrobial compounds. To avoid infection with phytopathogenic bacteria, nitrogen-fixing rhizobial bacteria and leguminous plants have developed complex signal exchange mechanisms that allow a specific bacterial strain to induce its specific host plant species to form invasion structures through which the bacteria can enter the plant root [52]. The evidence of co-evolution presented here suggested that MsSN1 peptide could be part of the battery of compounds involved in discriminating the symbionts from other microbes, so as to allow the beneficial infection and inhibit colonization of potentially pathogenic microbes.

In concordance with the hypothesis of plant-microbe coevolution, MsSN1-overexpressing transgenic plants showed nodule production of S. meliloti BL225C comparable with that of the wild type plants (Figure 8A-B), suggesting that $M s S N 1$ does not affect plant infection when nitrogen-fixing bacterial strains have an alfalfa origin. Then, to explore the effect of $M s S N 1$ on free living strains of rhizobacteria as Pseudomonas, the antimicrobial activity of $M s \mathrm{SN} 1$ on P. fluorescens Pf-5 isolated from soil samples was studied. Interestingly, P. fluorescens Pf-5 showed hypersensitivity to the MsSN1extract
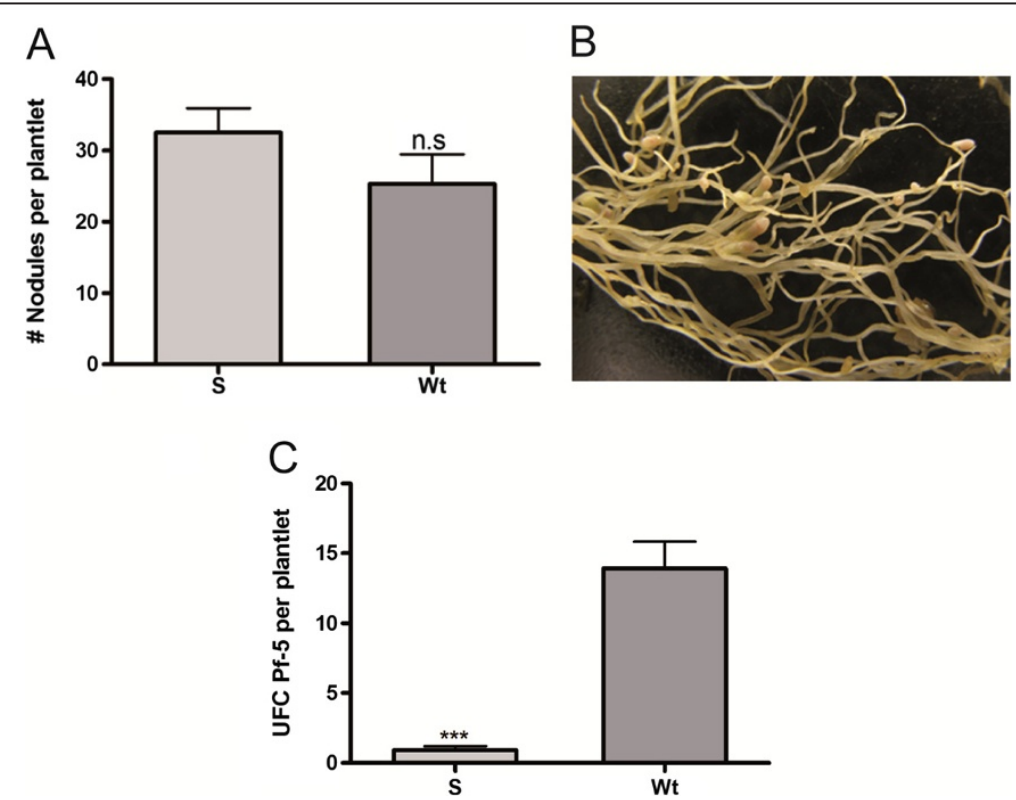

Figure 8 Bacterial colonization of MsSN1-overexpressing transgenic plants. Analysis of alfalfa-Sinorhizobium meliloti BL225C interactions: number of nodules in two-month-old alfalfa plants. (A) Photo of nodulated root. (B) Study of alfalfa colonization by Pseudomonas fluorescens Pf-5. (C) MSSN1-overexpressing plants. Wt: wild type. All values are means \pm SEM $(n=20)$. N.S: non-significant, ${ }^{* * *} \mathrm{p}<0.001$, t-test. 
(Zone of inhibition $=1.76 \pm 0.06 \mathrm{~mm}$ ). In agreement with the in vitro activity of MsSN1, P. fluorescens Pf-5 showed differential proliferation in the rhizosphere of wild type and transgenic lines of alfalfa 30 days after inoculation, suggesting an increased antibacterial activity in MsSN1overexpressing plants (Figure $8 \mathrm{C}$ ). These results show additional in vitro and in vivo evidence of $M s \mathrm{SN} 1$ as a part of the innate immune response and the wide range of activity of $M s \mathrm{SN} 1$.

\section{Conclusions}

Previous studies and the results reported here show that snakin peptides have important and ancestral roles in land plant innate immunity. Interestingly, MsSN1-overexpressing alfalfa transgenic plants show increased antimicrobial activity against virulent fungal strains without altering the nitrogen-fixing symbiosis, opening the way to the production of effective alfalfa transgenic cultivars for biotic stress resistance. In this work, data also suggest a coevolutionary process, in which alfalfa exerts a selection pressure for resistance to $M s \mathrm{SN} 1$ on rhizobial bacteria.

\section{Additional files}

\section{Additional file 1: Table of primers used in this work. \\ Additional file 2: Similarity of the product of MsSN1 gene to other snakin/GASA proteins from plants. \\ Additional file 3: Alfalfa transformation. \\ Additional file 4: Identity of the product of MsSN1 gene to other snakin/GASA proteins from Arabidopsis. \\ Additional file 5: RT-PCR studies of MsSN1 gene expression in E. coli pSJ33 (1) and E. coli pSJ33-MsSN (2) strains. \\ Additional file 6: RT-PCR assays showing MsSN1 expression in young floral buds (A-B), leaves (C-D), stems (E-F) and roots (G-H). Additional file 7: Molecular characterization of transgenic alfalfa lines overexpressing MsSN1.}

Additional file 8: Vigor phenotype of transgenic (S1) and wild type (Wt) alfalfa plants.

Additional file 9: Phylogenetic analysis of fungal strains isolated from alfalfa.

\section{Competing interests}

The authors declare that they have no competing interests.

\section{Authors' contributions}

Conceived and designed the experiments: GCS; NDA; JPM; MEP. Performed the experiments: ANG; NDA; GCS; ARF; MCG; MJD. Analyzed the data: GS; NDA. Wrote the paper: GS; NDA; CAB. All authors read and approved the final manuscript.

\section{Acknowledgments}

In memory of Ing. Agr. Raúl Ríos.

We thank Carmen Soria, Juan Riquelme and Guillermo Piparola (IGEAF-INTA) for their technical support.

This work was supported by Agencia Nacional de Promoción Científica y Tecnológica (grant PICT 2011-1325). NDA; CAB; JPM and GCS are researchers of the National Scientific and Technical Research Council (CONICET)

\section{Author details}

'Instituto de Genética Ewald A. Favret (CICVyA-INTA), De los Reseros S/N, Castelar C25 (1712), Buenos Aires, Argentina. Instituto de Investigaciones Biomédicas en Retrovirus y SIDA (INBIRS), UBA-CONICET, Paraguay 2155,

C1121ABG Ciudad Autónoma de Buenos Aires, Argentina. ${ }^{3}$ Departamento de Biodiversidad y Biología Experimental, Facultad de Ciencias Exactas y Naturales, Universidad de Buenos Aires, Intendente Güiraldes 2160, Ciudad Universitaria, Pabellón II, C1428EGA Ciudad Autónoma de Buenos Aires, Argentina. ${ }^{4}$ Instituto de Investigaciones en Ingeniería Genética y Biología Molecular, "Dr. Hector Torres", (INGEBI-CONICET), Vuelta de Obligado 2490, C1428ADN Ciudad Autónoma de Buenos Aires, Argentina.

Received: 20 June 2014 Accepted: 11 September 2014

Published online: 17 September 2014

\section{References}

1. Volenec JJ, Cunningham SM, Haagenson DM, Berg WK, Joern BC, Wiersma DW: Physiological genetics of alfalfa improvement: past failures, future prospects. Field Crops Res 2002, 75:97-110.

2. Lopez-Solanilla E, Garcia-Olmedo F, Rodriguez-Palenzuela P: Inactivation of the sapA to sapF locus of Erwinia chrysanthemi reveals common features in plant and animal bacterial pathogenesis. Plant Cell 1998, 10(6):917-924

3. Segura A, Moreno M, Madueno F, Molina A, Garcia-Olmedo F: Snakin-1, a peptide from potato that is active against plant pathogens. Mol Plant Microbe Interact 1999, 12(1):16-23.

4. Berrocal-Lobo M, Segura A, Moreno M, Lopez G, Garcia-Olmedo F, Molina A: Snakin-2, an antimicrobial peptide from potato whose gene is locally induced by wounding and responds to pathogen infection. Plant Physiol 2002, 128(3):951-961.

5. Kovalskaya N, Hammond RW: Expression and functional characterization of the plant antimicrobial snakin-1 and defensin recombinant proteins. Protein Expr Purif 2009, 63(1):12-17.

6. Rong W, Qi L, Wang J, Du L, Xu H, Wang A, Zhang Z: Expression of a potato antimicrobial peptide $\mathrm{SN} 1$ increases resistance to take-all pathogen Gaeumannomyces graminis var. tritici in transgenic wheat. Funct Integr Genomics 2013, 13(3):403-409.

7. Guzman-Rodriguez JJ, Ibarra-Laclette E, Herrera-Estrella L, Ochoa-Zarzosa A, Suarez-Rodriguez LM, Rodriguez-Zapata LC, Salgado-Garciglia R, JimenezMoraila B, Lopez-Meza JE, Lopez-Gomez R: Analysis of expressed sequence tags (ESTs) from avocado seed (Persea americana var. drymifolia) reveals abundant expression of the gene encoding the antimicrobial peptide snakin. Plant Physiol Biochem 2013, 70:318-324.

8. Meiyalaghan S, Thomson SJ, Fiers MW, Barrell PJ, Latimer JM, Mohan S, Jones EE, Conner AJ, Jacobs JM: Structure and expression of GSL1 and GSL2 genes encoding gibberellin stimulated-like proteins in diploid and highly heterozygous tetraploid potato reveals their highly conserved and essential status. BMC Genomics 2014, 15:2.

9. Mohan S, Meiyalaghan S, Latimer JM, Gatehouse ML, Monaghan KS, Vanga BR, Pitman AR, Jones EE, Conner AJ, Jacobs JM: GSL2 over-expression confers resistance to Pectobacterium atrosepticum in potato. Theor Appl Genet 2014, 127(3):677-689.

10. Almasia NI, Bazzini AA, Hopp HE, Vazquez-Rovere C: Overexpression of snakin-1 gene enhances resistance to Rhizoctonia solani and Erwinia carotovora in transgenic potato plants. Mol Plant Pathol 2008, 9(3):329-338.

11. Balaji V, Smart CD: Over-expression of snakin-2 and extensin-like protein genes restricts pathogen invasiveness and enhances tolerance to Clavibacter michiganensis subsp. michiganensis in transgenic tomato (Solanum lycopersicum). Transgenic Res 2012, 21(1):23-37.

12. Kovalskaya N, Zhao Y, Hammond RW: Antibacterial and antifungal activity of a snakin-defensin hybrid protein expressed in tobacco and potato plant. Open Plant Sci J 2011, 5:29-42.

13. Balaji V, Sessa G, Smart CD: Silencing of host basal defense responserelated gene expression increases susceptibility of Nicotiana benthamiana to Clavibacter michiganensis subsp. michiganensis. Phytopathology 2011, 101(3):349-357.

14. Nahirñak V, Almasia NI, Fernandez PV, Hopp HE, Estevez JM, Carrari F, Vazquez-Rovere C: Potato snakin-1 gene silencing affects cell division, primary metabolism, and cell wall composition. Plant Physiol 2012, 158(1):252-263. 
15. Nahirñak V, Almasia NI, Hopp HE, Vazquez-Rovere C: Snakin/GASA proteins: involvement in hormone crosstalk and redox homeostasis. Plant Signal Behav 2012, 7(8):1004-1008

16. Porto WF, Franco OL: Theoretical structural insights into the snakin/GASA family. Peptides 2013, 44:163-167.

17. Howell CR, Stipanovic RD: Control of Rhizoctonia solani on cotton seedlings with Pseudomonas fluorescens with an antibiotic produced by the bacterium. Phytopathology 1979, 69:480-482.

18. Carelli M, Gnocchi S, Fancelli S, Mengoni A, Paffetti D, Scotti C, Bazzicalupo M: Genetic diversity and dynamics of Sinorhizobium meliloti populations nodulating different alfalfa cultivars in Italian soils. Appl Environ Microbiol 2000, 66(11):4785-4789.

19. Selbitschka W, Keller M, Miethling-Graff R, Dresing U, Schwieger F, Krahn I, Homann I, Dammann-Kalinowski T, Puhler A, Tebbe CC: Long-term field release of bioluminescent Sinorhizobium meliloti strains to assess the influence of a recA mutation on the strains' survival. Microb Ecol 2006, 52(3):583-595.

20. Reeve W, Chain P, O'Hara G, Ardley J, Nandesena K, Brau L, Tiwari R, Malfatti S, Kiss H, Lapidus A, Copeland A, Nolan M, Land M, Hauser L, Chang YJ, Ivanova N, Mavromatis K, Markowitz V, Kyrpides N, Gollagher M, Yates R, Dilworth M, Howieson J: Complete genome sequence of the Medicago microsymbiont Ensifer (Sinorhizobium) medicae strain WSM419. Stand Genomic Sci 2010, 2(1):77-86.

21. Keyser HH, Bohlool BB, Hu TS, Weber DF: Fast-growing rhizobia isolated from root nodules of soybean. Science 1982, 215(4540):1631-1632.

22. Eardly BD, Hannaway DB, Bottomley PJ: Characterization of Rhizobia from ineffective Alfalfa nodules: ability to nodulate bean plants [Phaseolus vulgaris (L.) Savi.]. Appl Environ Microbiol 1985, 50(6):1422-1427.

23. Segovia L, Young JP, Martinez-Romero E: Reclassification of American Rhizobium leguminosarum biovar phaseoli type I strains as Rhizobium etli sp. nov. Int J Syst Bacteriol 1993, 43(2):374-377.

24. Kaneko T, Nakamura Y, Sato S, Asamizu E, Kato T, Sasamoto S, Watanabe A, Idesawa K, Ishikawa A, Kawashima K, Kimura T, Kishida Y, Kiyokawa C, Kohara M, Matsumoto M, Matsuno A, Mochizuki Y, Nakayama S, Nakazaki N, Shimpo S, Sugimoto M, Takeuchi C, Yamada M, Tabata S: Complete genome structure of the nitrogen-fixing symbiotic bacterium Mesorhizobium loti (supplement). DNA Res 2000, 7(6):381-406.

25. Mathis JN, Israel DW, Barbour WM, Jarvis BD, Elkan GH: Analysis of the symbiotic performance of bradyrhizobium japonicum USDA 110 and its derivative $\mathrm{I}-110$ and discovery of a new mannitol-utilizing, nitrogenfixing USDA 110 derivative. Appl Environ Microbiol 1986, 52(1):75-80.

26. Hoekema A, Hirsch PR, Hooykaas PJJ, Schilperoort RA: A binary plant vector strategy based on separation of vir- and T-region of the Agrobacterium tumefaciens Ti-plasmid. Nature 1983, 303(5913):179-180.

27. Setten L, Soto G, Mozzicafreddo M, Fox AR, Lisi C, Cuccioloni M, Angeletti M, Pagano E, Diaz-Paleo A, Ayub ND: Engineering Pseudomonas protegens Pf-5 for nitrogen fixation and its application to improve plant growth under nitrogen-deficient conditions. PLoS One 2013, 8(5):e63666.

28. Ayub ND, Julia Pettinari M, Mendez BS, Lopez NI: Impaired polyhydroxybutyrate biosynthesis from glucose in Pseudomonas sp. $14-3$ is due to a defective beta-ketothiolase gene. FEMS Microbiol Lett 2006, 264(1):125-131.

29. Gleave AP: A versatile binary vector system with a T-DNA organisational structure conducive to efficient integration of cloned DNA into the plant genome. Plant Mol Biol 1992, 20(6):1203-1207.

30. Campanella JJ, Bitincka L, Smalley J: MatGAT: an application that generates similarity/identity matrices using protein or DNA sequences. BMC Bioinformatics 2003, 4:29.

31. Tamura K, Peterson D, Peterson N, Stecher G, Nei M, Kumar S: MEGA5: molecular evolutionary genetics analysis using maximum likelihood, evolutionary distance, and maximum parsimony methods. Mol Biol Evol 2011, 28(10):2731-2739.

32. Finn RD, Mistry J, Tate J, Coggill P, Heger A, Pollington JE, Gavin OL, Gunasekaran P, Ceric G, Forslund K, Holm L, Sonnhammer EL, Eddy SR: The Pfam protein families database. Nucleic Acids Res 2010, 38(Database issue):D211-D222.

33. Shen HB, Chou KC: Signal-3 L: a 3-layer approach for predicting signal peptides. Biochem Biophys Res Commun 2007, 363(2):297-303.

34. Moller EM, Bahnweg G, Sandermann H, Geiger HH: A simple and efficient protocol for isolation of high molecular weight DNA from filamentous fungi, fruit bodies, and infected plant tissues. Nucleic Acids Res 1992, 20(22):6115-6116.
35. Ayub ND, Pettinari MJ, Ruiz JA, Lopez NI: A polyhydroxybutyrateproducing Pseudomonas sp. isolated from Antarctic environments with high stress resistance. Curr Microbiol 2004, 49(3):170-174.

36. Beringer JE: $\mathrm{R}$ factor transfer in Rhizobium leguminosarum. J Gen Microbiol 1974, 84(1):188-198.

37. Shen WJ, Forde BG: Efficient transformation of Agrobacterium spp. by high voltage electroporation. Nucleic Acids Res 1989, 17(20):8385.

38. D'Halluin K, Botterman J, De Greef W: Engineering of herbicide-resistant Alfalfa and evaluation under field conditions. Crop Sci 1990, 30:866-871.

39. Soto G, Fox R, Ayub N, Alleva K, Guaimas F, Erijman EJ, Mazzella A, Amodeo $G$, Muschietti J: TIP5; 1 is an aquaporin specifically targeted to pollen mitochondria and is probably involved in nitrogen remobilization in Arabidopsis thaliana. Plant J 2010, 64(6):1038-1047.

40. Sanchez L, Weidmann S, Arnould C, Bernard AR, Gianinazzi S, GianinazziPearson V: Pseudomonas fluorescens and Glomus mosseae trigger DMI3-dependent activation of genes related to a signal transduction pathway in roots of Medicago truncatula. Plant Physiol 2005, 139(2):1065-1077.

41. Perez Di Giorgio J, Soto G, Alleva K, Jozefkowicz C, Amodeo G, Muschietti $J P$, Ayub ND: Prediction of aquaporin function by integrating evolutionary and functional analyses. J Membr Biol 2014, 247(2):107-125.

42. Furukawa T, Sakaguchi N, Shimada H: Two OsGASR genes, rice GAST homologue genes that are abundant in proliferating tissues, show different expression patterns in developing panicles. Genes Genet Syst 2006, 81:171-180.

43. Roxrud I, Lid SE, Fletcher JC, Schmidt ED, Opsahl-Sorteberg HG: GASA4, one of the 14-member Arabidopsis GASA family of small polypeptides, regulates flowering and seed development. Plant Cell Physiol 2007, 48(3):471-483.

44. Bennici A: Origin and early evolution of land plants: Problems and considerations. Commun Integr Bio/ 2008, 1(2):212-218.

45. Choi HK, Kim D, Uhm T, Limpens E, Lim H, Mun JH, Kalo P, Penmetsa RV Seres A, Kulikova O, Roe BA, Bisseling T, Kiss GB, Cook DR: A sequencebased genetic map of Medicago truncatula and comparison of marker colinearity with M. sativa. Genetics 2004, 166(3):1463-1502.

46. Cook DR: Medicago truncatula-a model in the making! Curr Opin Plant Biol 1999, 2(4):301-304

47. McCann MC, Rogan GJ, Fitzpatrick S, Trujillo WA, Sorbet R, Hartnell GF, Riodan SG, Nemeth MA: Glyphosate-tolerant alfalfa is compositionally equivalent to conventional alfalfa (Medicago sativa L.). J Agr Food Chem 2006, 54(19):7187-7192.

48. Masoud SA, Zhu Q, Lamb C, Dixon RA: Constitutive expression of an inducible glucanase in alfalfa reduces disease severity caused by the oomycete pathogen Phytophthora megasperma f. sp medicaginis, but does not reduce disease severity of chitin-containing fungi. Transgenic Res 1996, 5:313-323.

49. Hipskind JD, Paiva NL: Constitutive accumulation of a resveratrolglucoside in transgenic alfalfa increases resistance to Phoma medicaginis. Mol Plant Microbe Interact 2000, 13(5):551-562.

50. Gruenheid S, Le Moual H: Resistance to antimicrobial peptides in Gramnegative bacteria. FEMS Microbiol Lett 2012, 330(2):81-89.

51. Doyle JJ: Phylogenetic perspectives on the origins of nodulation. Mol Plant Microbe Interact 2011, 24(11):1289-1295.

52. Jones KM, Kobayashi H, Davies BW, Taga ME, Walker GC: How rhizobial symbionts invade plants: the Sinorhizobium-Medicago model. Nat Rev Microbiol 2007, 5(8):619-633.

\section{doi:10.1186/s12870-014-0248-9}

Cite this article as: García et al:: Alfalfa snakin-1 prevents fungal colonization and probably coevolved with rhizobia. BMC Plant Biology $201414: 248$ 